\title{
Dimas Rosa: duplamente um grande mestre
}

Sandra Nunes

Sandra Regina Ramalbo e Oliveira 
Este ensaio ${ }^{1}$ tenta trazer para o presente um pouco do que fez e de quem foi Dimas Rosa, especialmente para o ensino da arte catarinense nas escolas: homem de talentos múltiplos descobriu, em materiais diversos, distintas linguagens para se expressar. Foi membro do Grupo Sul, importante movimento artístico catarinense. Paralela à vida de artista, deixou grande legado para a Educação. Professor e Diretor do Instituto Estadual de Educação, foi um dos mentores do Curso de Educação Artística da UDESC e primeiro Diretor Geral do Centro de Artes da mesma Universidade. Desenhista, pintor, gravador, ceramista, escultor em madeira, metal, poliéster, fibra de vidro, além de teórico: um artista modernista, cuja figura humana sobrepuja a obra.

Palavras-chave: Arte Catarinense; Modernismo; Dimas Rosa.

\section{Aspectos do contexto}

T evou um bom tempo para que, em Santa Catarina, os artistas Uvivessem exclusivamente da sua arte e hoje ainda os casos são raros. Durante o período modernista, melhor dizendo, no espaço ocupado pela arte considerada modernista, portanto, mais por suas características do que pelo período na qual foi produzida, em Santa Catarina, a maioria dos artistas eram, tecnicamente, diletantes.

Isto quer dizer que entre os modernistas catarinenses havia na maioria dos casos uma atividade que lhes ocupava prioritariamente o tempo, horas e horas gastas no desempenho de profissóes paralelas, nem sempre compatíveis com o fazer artístico, como no caso de Meyer Filho, bancário que ficava esboçando galos em formulários e criando imagens com a impressão dos burocráticos carimbos. Outros conseguiram desempenhar funçóes em áreas correlacionadas à arte, como professor de desenho, artístico ou geométrico, em uma época na qual o ensino de arte náo era obrigatório no ensino básico; ou artista gráfico, naquele tempo, denominada "ilustrador". Foi o caso de Hassis, Aldo Nunes e Dimas Rosa.

Dimas Rosa, antes de ser professor universitário, entre tantas

\footnotetext{
${ }^{1}$ Ensaio integrante do Projeto de Pesquisa Academicismo e Modernismo em Santa Catarina. In: MAKOWIECKY, S.; CHEREM, R. M.. Academismo e Modernismo em Santa Catarina. 1. ed. Florianópolis: Editora da UDESC, 2010. v. 1.705p. CD-ROM. O texto sofreu pequenas alteraçóes para esta publicação.
} 
outras atividades e funçóes das quais se ocupou, foi professor de Desenho Geométrico no ensino básico. Difícil avaliar tanto o desempenho de um professor quanto a de um artista, pois a repercussão do trabalho de ambos, além de se dar a longo prazo, dilui-se no conjunto da sociedade. Assim, não se pode avaliar se Dimas Rosa foi melhor professor ou artista: o certo é que deixou muitas marcas; para quem o conheceu e com ele conviveu, certamente, mais do que a do artista ou o a do professor, prevalece a figura do ser humano.

Em uma época na qual o professor era considerado uma autoridade, independentemente do fato de ser autoritário ou não, Dimas Rosa, que fazia parte do segundo tipo, era professor de escola pública. $\mathrm{O}$ professor era autoridade pelo simples fato de que o conhecimento era a via mais reconhecida para a ascensão social, e ele, o professor, o meio para tal. Tanto é que, nas pequenas cidades, nas cerimônias oficiais, o professor figurava em destaque junto ao prefeito, ao padre, ao juiz e, às vezes, ao médico. Ou seja, as autoridades máximas das dimensóes mais importantes da vida em sociedade.

Nesse tempo passado, quando o professor do ensino básico era uma autoridade, ao invés de quadro branco com caneta, as salas de aula tinham o quadro negro. E nele o professor escrevia ou desenhava - geralmente, com giz branco. Foi nesta época que os alunos do Instituto Estadual de Educação tiveram um professor de Desenho Geométrico que se celebrizou por, com a mão esquerda, pois era canhoto, desenhar circunferências com giz sobre o quadro negro. E ao terminar, marcava o seu centro, "a olho", entâo pegava o grande compasso de madeira e conferia a precisão da circunferência desenhada "a mão livre". Era Dimas Rosa.

Quando do início desta pesquisa, a família de Dimas Rosa nos deu acesso a documentos, muitos deles, originais. Tudo ordenado em pastas, como se fossem preparadas para nos entregar, dias antes, sabendo do nosso propósito. Apenas o cheiro do passado denunciava que as pastas foram organizadas há muitos anos, por ele mesmo. Pudemos então testemunhar o quanto Dimas Rosa era também organizado e preciso, tanto quanto nas suas atitudes.

$\mathrm{O}$ que teria tudo isso a ver (o diletantismo dos artistas, a compatibilidade entre o exercício de uma profissão convencional e a respectiva produção artística, o fazer de um professor de desenho geométrico com habilidades peculiares, documentos póstumos 
muito bem organizados) com o modernismo?

Primeiro, que não havia em Santa Catarina, na segunda metade do século passado, um mercado de arte, como já havia para o modernismo, em centros urbanos maiores do país. Segundo, que dada essa lacuna, os artistas eram diletantes, sobrevivendo de outras ocupaçôes. Não havia ainda o apoio governamental sistematizado, como as leis de incentivo que hoje existem. Mas havia, contudo, preocupação do poder público, um tanto paternalista, é verdade, à moda da época, como a concessão de empregos públicos aos artistas, em áreas correlacionadas, como educação e cultura, bem como a aquisição de obras para o adorno de edifícios públicos.

Estas práticas dizem respeito ao conjunto dos artistas da época, mas acabaram por nos brindar, no caso de Dimas Rosa, talvez com o melhor professor de Desenho Geométrico que o Estado já teve, responsável pelos conhecimentos de geraçôes de cidadãos. E, igualmente, com um dos melhores e mais versáteis professores de ensino superior do Estado, na área de Artes Visuais, transitando do verbal da teoria para o visual dos processos artísticos, em intertextualidades permanentes.

Por outro lado, entre as habilidades peculiares de Dimas, professor de Desenho, a ordem em seus documentos, organizados por ele mesmo, herança que ora compartilhamos com seus descendentes, bem como sua produção artística, tudo isto têm em comum sua obsessão pela perfeição formal, sua persistência, determinação, disciplina, dedicação a tudo o que fazia, seu rigor e seu trabalho.

Além de professor de disciplinas teóricas, manifestou-se em diversas técnicas, por meio de distintos materiais ou, como diríamos agora, por meio de diferentes linguagens: além de preencher uma lacuna para os professores de arte nas escolas, quando precisam ensinar arte catarinense e não encontram muito material disponível, este trabalho pretende talvez provocar o início de mais estudos sobre uma figura ímpar e sua obra múltipla.

Chamamos os artistas de mestres; os grandes artistas, de grandes mestres. Chamamos os professores de mestres, igualmente; por consequência, os grandes professores, de grandes mestres. Aqui tratamos da vida e da obra de Dimas Rosa, duplamente um grande mestre. 


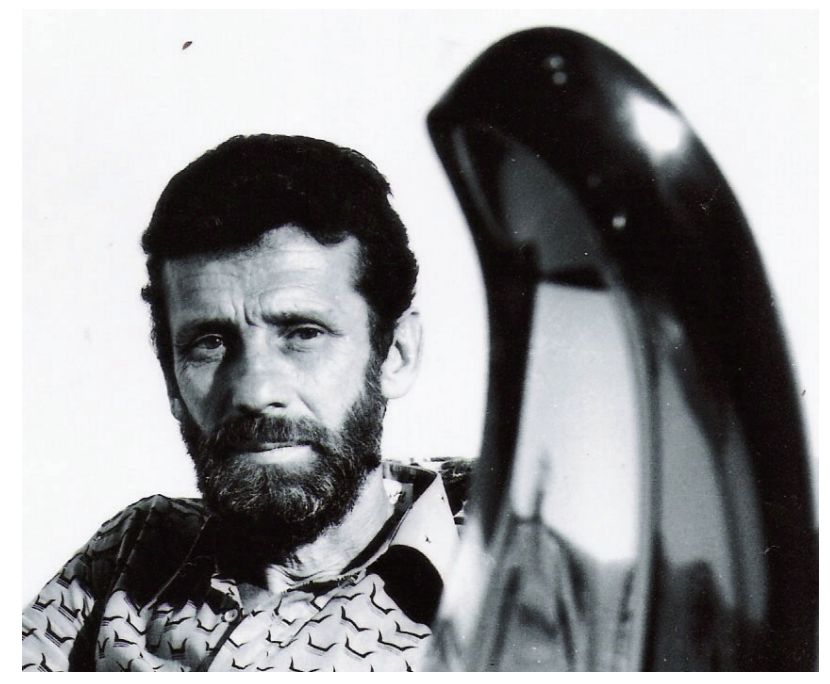

Figura 1- Fotografia de Dimas Rosa. Sem data. Em primeiro plano, uma de suas Madonas.

\section{Dimas Rosa: o professor}

imas exerceu a atividade docente em diferentes níveis do ensino formal, iniciando como professor regente de ensino primário ${ }^{2}$ no Instituto de Educação e Colégio Estadual Dias Velho, em 1954, chegando ao cargo de Professor Titular no curso de Educação Artística da Faculdade de Educação da Universidade do Estado de Santa Catarina (UDESC) ${ }^{3}$.

A partir de 1954, passou a lecionar Desenho Geométrico em diferentes instituiçóes públicas e particulares da capital catarinense, destacando-se, dentre outros, o período de 1954 a 1971 em que foi professor no Instituto de Educação e Colégio Estadual Dias Velho, atualmente denominado Instituto Estadual de Educação, bem como, de 1958 a 1969, quando lecionou no Curso Científico do Colégio Catarinense. Em 1971, passou a ocupar o cargo de Professor de Ensino Médio e, posteriormente, foi colocado à disposição da Faculdade de Educação da UDESC.

\footnotetext{
${ }^{2}$ Atualmente denominado Séries Iniciais do Ensino Fundamental.

${ }^{3} \mathrm{Na}$ época em que Dimas iniciou sua carreira como professor universitário, esta instituiçẫo chamava-se Universidade para o Desenvolvimento do Estado de Santa Catarina.
} 
Nesse ínterim, Dimas Rosa cursou Licenciatura em Desenho e Plásticas pelo Instituto de Artes da Universidade Federal do Rio Grande do Sul (UFRGS), iniciado em 1970 e concluído em 1973. Nesta instituição atuou como estagiário no Departamento de Artes Visuais de 1971 a 1973, lecionando as disciplinas de História da Arte e História da Arte do Brasil.

Nesse ínterim, Dimas Rosa cursou Licenciatura em Desenho e Plásticas pelo Instituto de Artes da Universidade Federal do Rio Grande do Sul (UFRGS), iniciado em 1970 e concluído em 1973. Nesta instituição atuou como estagiário no Departamento de Artes Visuais de 1971 a 1973, lecionando as disciplinas de História da Arte e História da Arte do Brasil.

Em 1974 tornou-se Professor Titular da UDESC, no curso de Educação Artística, sendo fundamental para sua implementação ${ }^{4}$. Lecionou distintas disciplinas, tanto no curso de habilitação em Artes Plásticas, como no de habilitação em Desenho, podendo ser citadas, dentre outras: Elementos Estéticos; História da Arte; Desenho; Didática Especial e Prática de Ensino de Desenho; Técnicas Industriais III; Técnicas e Expressão e Comunicação Visuais - Modelagem, Cerâmica e Escultura I e II, o que mostra sua versatilidade e suas competências interdisciplinares. Atuou ainda como Professor da Universidade Federal de Santa Catarina (UFSC), nos cursos de Engenharia Civil, Mecânica e Elétrica (1974-1975), tornando-se Professor Assistente desta instituiçấo a partir de 1981.

Dimas Rosa aliou a carreira de docente com a de cargos administrativos ligados à Educação, destacando-se o de Diretor Geral do Instituto Estadual de Educação (1965-1967 e 1967-1969); o de Conselheiro do Conselho Estadual de Educação de Santa Catarina (1966-1969); o de Chefe de Departamento de Artes Visuais da UDESC (1976-1978); e o de primeiro Diretor Geral do Centro de Artes da UDESC (1985).

Estes são dados objetivos, ou formais, ou burocráticos, talvez os que têm validade para o mundo real. Mas o que não pode ser esquecido é o modo como seu magistério foi exercido. Desde as turmas enormes de alunos, nem sempre motivadas, no ensino básico,

\footnotetext{
${ }^{4}$ Publicou no Jornal da UDESC, em 1976, o artigo “Arte ou Lixo?” - observaçôes acerca da Educaçấo Artística em Santa Catarina. Nele, justifica a necessidade do Estado em possuir instituiçóes de ensino capazes de formar profissionais para lecionarem a disciplina que se tornava obrigatória pela Lei 5692; e compara a realidade catarinense a dos Estados vizinhos que possuíam instituiçóes consolidadas há muito tempo.
} 
até os alunos de ensino superior, Dimas sempre foi um professor humano, amigo, não que fosse transigente: ele era justo. Do mesmo modo o foi, no exercício das atividades da administração escolar e universitária.

Em 27 de abril de 1993, o Egrégio Conselho Universitário da UDESC concedeu o título de Professor Emérito a Dimas Rosa, uma honraria concedida a muito poucos professores em toda a história da Instituição.

\section{Dimas Rosa: o artista}

pós um momento de efervescência na arte brasileira, em virtude do Aresultado das mudanças propostas pelos artistas modernistas, na década de 20, demorou um pouco para que tais ideias influenciassem os artistas locais. Talvez isto se deva ao distanciamento geográfico entre Santa Catarina e as cidades que, de maneira geral, se destacavam no cenário artístico nacional - principalmente em São Paulo e Rio de Janeiro, como também pela dificuldade de acesso a publicaçóes, aos meios de comunicação, de transporte e pela falta de instituiçóes de ensino neste campo.

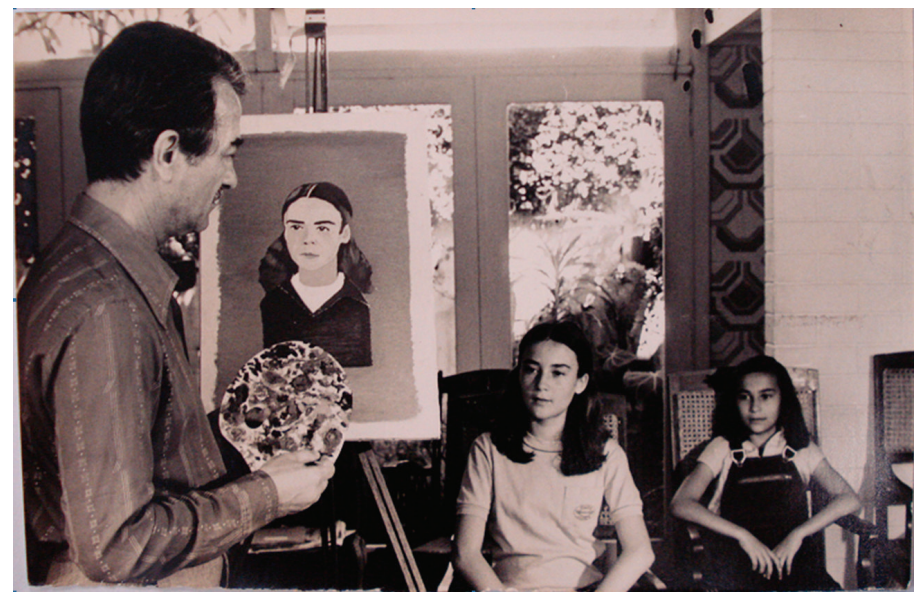

Figura 2 - Fotografia de Dimas Rosa pintando um retrato. Sem data. Acervo da Fundação Catarinense de Cultura/FCC. 
Os primeiros sinais $\mathrm{da}$ influência modernista na arte catarinense foram percebidos nos anos 40, principalmente a partir da organização entre intelectuais, poetas, artistas plásticos e cineastas ${ }^{5}$ que fundaram, em 1947, o Círculo de Arte Moderna (CAM), mais tarde conhecido como "Grupo Sul", uma referência a sua publicação impressa, a chamada "Revista Sul". Eles lançaram as bases de uma arte mais identificada com a cultura local e foram responsáveis pelo que poderia ser denominado de modernismo catarinense, tardio cronologicamente, mas fundamental para as mudanças e as conquistas para a arte local. Fizeram parte do Grupo Sul: Salim Miguel, Silveira de Souza, Eglê Malheiros, Aldo Nunes, Jason César, Ody Fraga, Hugo Mund Jr., Guido Wilmar Sassi, Ernesto Meyer Filho e Dimas Rosa.

Estes artistas buscavam estabelecer os contornos de uma imagem local, tal como fizeram os modernistas de 22, buscando uma imagem brasileira. Ao eleger estes artistas, eles tiraram o foco de Victor Meirelles e a ideia de construção de um Brasil, baseada em grandes personagens e fatos históricos, símbolo máximo da arte acadêmica que neste momento, não interessava aos jovens artistas (MAKOWIECKY, 2009, p. 3).

Em 1948, a primeira edição da "Revista Sul” foi apresentada ao público com o intuito de propagar ideias de seus integrantes, bem como acompanhar e debater diferentes questóes envolvendo literatura, filosofia, arte, cultura. Também serviu para expor as produçóes dos artistas plásticos locais, principalmente por meio de ilustraçôes, como aconteceu com Dimas Rosa (1956). A Revista, editada por dez anos, sustentou a aglutinação e continuidade do Grupo, como também as discussóes que aconteciam, principalmente, na Livraria Anita Garibaldi, de propriedade de Salim Miguel, expoente do Grupo Sul.

Com a primeira exposição de arte moderna em Florianópolis, também no ano de 1948, seu idealizador, o escritor Marques Rebelo, lançou as bases para a fundação do Museu de Arte Moderna de Florianópolis ${ }^{6}$, concretizado um ano mais tarde, tornando-se um dos primeiros museus de arte moderna do país e fundamental para o cenário artístico local. Foi nesta exposição que obras dos artistas

\footnotetext{
${ }^{5}$ Sob a responsabilidade do Grupo Sul foi produzido, em 1957, "O Preço da Ilusão", primeiro longa-metragem totalmente catarinense.

${ }^{6}$ A partir de 1970 passou a ser chamado Museu de Arte de Santa Catarina, instituiçâao vinculada a Fundaçẫo Catarinense de Cultura.
} 
modernos da década de 20, que promoveram a Semana de Arte Moderna em São Paulo, foram dados a conhecer à sociedade local.

Cabe citar, nesse panorama, a importância da criação, em 30 de janeiro de 1958, do Grupo de Artistas Plásticos de Florianópolis $(\mathrm{GAPF})^{7}$, com o intuito de incentivar as artes plásticas; de oferecer formação por meio de cursos, palestras e estudos; e de realizar, anualmente, um saláo com obras de seus componentes. Foram membros fundadores: Hugo Mund Júnior, Ernesto Meyer Filho, Tércio da Gama, Pedro Paulo Vecchietti, Heidy de Assis Corrêa (Hassis), Rodrigo de Haro, Thales Brognoli, Aldo Nunes e Dimas Rosa (CORREAA, 1978). Quase todos os integrantes do GAPF, com exceçáo Hugo Mund, não tinham frequentado escolas de arte, ao menos até a ocasiáo em que formaram o Grupo, e construíram sua obra a partir de pesquisas pessoais, como também exerciam outras profissóes, tais como bancário, funcionário autártico, professor, comerciário e advogado. Sobre isto, o crítico Carlos Humberto Corrêa nos diz:

Talvez pelo fato de que nenhum dos artistas que iniciaram ou acompanharam o movimento nos seus primeiros tempos tenha tido qualquer formação acadêmica, sendo todos, sem exceção, auto-didatas e, em consequência, tenham trazido formaçóes diferentes o que lhes proporcionou uma visão de arte também diferente, talvez por este fato, o Grupo tenha se conservado homogêneo em seus propósitos sem, entretanto, impor conceitos estéticos ou fórmulas discutíveis a qualquer de seus membros. E, justamente também por este fato, proporcionou o desenvolvimento individual de cada um ou a estagnação de outros e consequentemente seus afastamentos (apud CORRÊA, 1978 , não paginado).

Nesse contexto, o jovem artista Dimas Rosa, se inseriu no cenário artístico local, preservando sua individualidade e suas convicçóes, mas não deixando de se relacionar com seus pares. Entretanto, aos poucos, alguns membros do GAPF, dentre eles Dimas, seguiram suas direções e não mais se interessaram pelo Grupo. Seus trabalhos caracterizam-se pelo relevo, textura e cor, quase todos abstratos. No entanto, por ele

\footnotetext{
${ }^{7}$ Neste mesmo ano, a Câmara Municipal de Florianópolis declara o Grupo como sendo de Utilidade Pública, por meio da Lei No 38. No ano de 2008, o Museu de Arte de Santa Catarina apresentou a exposição "GAPF 50 ANOS”, com 26 obras que fizeram parte da primeira exposiçăo do Grupo, em 1958.
} 
ser essencialmente escultor, os trabalhos de Dimas trazem a marca do tempo e do espaço.

Segundo Araújo (1979, p. 246), a obra desse artista pode ser dividida em três fases, caracterizadas pelo uso de técnicas e pela escolha de temáticas específicas. A primeira fase é mais realista, com interesse pelo registro do real, cenas do cotidiano, além de ser marcada por uso de técnicas bidimensionais (fig.3).

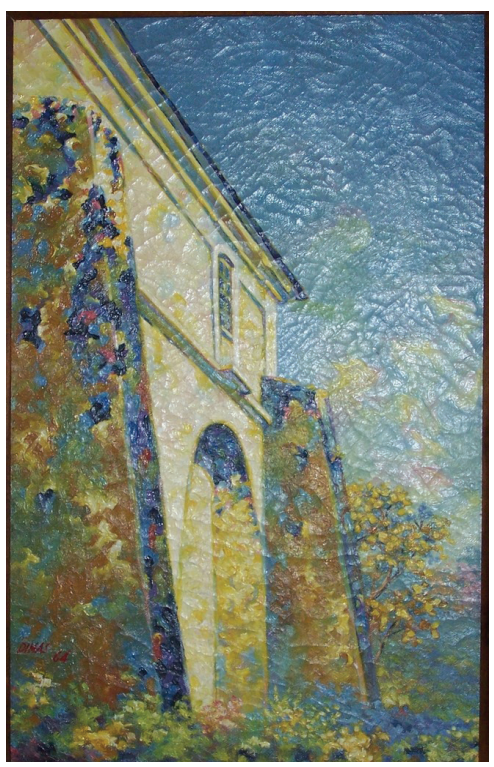

Figura 3 - Dimas Rosa. Detalhes de Anhatomirim. 1964. Óleo sobre tela. 25x38,5cm. Acervo Elisabeth Rosa.

A segunda poderia ser considerada uma fase transitória na utilização das técnicas (passagem da pintura para a escultura), porém muito específica com relação às questóes formais, que se distanciam da fase anterior, pois nesta Dimas vai propor jogos formais abstratos. Poder-se-ia dizer que para tanto contribuem, de um lado a influência da arte concreta, vigente ainda na época, e de outro sua própria bagagem de conhecimentos, ou seja, sua grande experiência no domínio da geometria, o que vinha a se encaixar perfeitamente nos 
ideais concretistas e até mesmo, nos minimalistas.

A última fase apresentada pela autora é caracterizada pela tridimensionalidade das obras, onde as figuras assumem um caráter "sintético e simbólico", evidenciados nas criações de máscaras; e um caráter "mais descompromissado" ao adquirirem mais dinamismo, a partir da busca pelo movimento nas formas (fig.4).

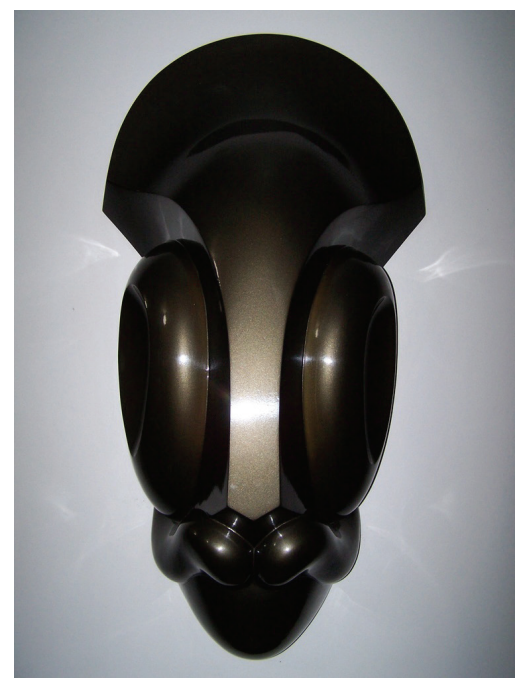

Figura 4 - Dimas Rosa. Máscara IV. 1977. Fibra de vidro e acrílica marrom castor. 58x 110x28cm. Acervo Dimas Ricardo Rosa.

A respeito da temática da terceira fase, é importante salientar que esta escolha se deve tanto as vivências pessoais quanto coletivas. Pessoais, devido às experiências de infância, onde Dimas construía suas máscaras a partir da papetagem ${ }^{8}$ de figuras criadas, previamente, em argila; coletiva, pela influência da máscara na sociedade atual, presente em personagens dos meios de comunicação de massa (histórias em quadrinho, programas de TV, filmes, por exemplo), como também nas manifestações folclóricas (carnaval, danças, rituais, dentre outras). Por sua vez, as figuras humanas em movimento

\footnotetext{
${ }^{8}$ Técnica que consiste na colagem de papel sobre uma base, ou seja, uma superfície utilizada como molde e que após a secagem são, geralmente, separadas.
} 
são conseguidas a partir de relevos e que, segundo Araújo (1979, p. 246), "a matéria densa aproxima-o do expressionismo; a leveza e o sentido decorativo do art nouveau".

Quanto às técnicas utilizadas por Dimas em suas obras, nas duas primeiras fases utilizou, basicamente, tinta a óleo sobre diferentes suportes, principalmente madeira; porém, na segunda fase, prevaleceu o uso do papeláo texturado comum.

Em suas máscaras, por outro lado, continuou a empregar a mesma técnica utilizada na infância, embora modificando os materiais, por meio de sucessivas experiências. Construía uma matriz com argila, gesso, látex ou borracha de silicone; como material para as obras propriamente, predominava o uso de diversos tipos de resina; nas peças laminadas, a resina era reforçada com fibra de vidro e o acabamento era feito com laca acrílica em cores metálicas.

Também fez experiências com cimento armado, bronze e latão. Às vezes, usava materiais e técnicas que aprendeu bisbilhotando oficinas e indústrias em São Paulo, Porto Alegre e Florianópolis, as quais, segundo ele mesmo, "aprendi por esforço próprio, e nunca foram abordados naquela época”, entre as quais ele destacava:

moldagem com látex e diversos tipos de borracha de silicone; laminaçáo por contato, de diferentes tipos de resina com base de poliéster e epóxi, reforçados com fibras de vidro tecidas, em manta e picada; e fundição com resinas de poliéster e epóxi, com e sem materiais de carga, superfícies lisas e texturadas, e coloraçáo incorporada à resina com efeito opaco, leitoso e transparente" (ARAÚJO, 1997, p. 254).

Dimas foi um artista que pesquisou o emprego em suas obras de materiais como o poliéster, a fibra de vidro, a laca acrílica, a partir de uma técnica muito pessoal, fruto de suas experimentaçóes. Frequentemente, utilizava mais de um tipo de material e de processo em uma mesma obra.

O que não se pode deixar de observar, além de todos os aspectos já ressaltados, quais sejam a luta contra o academicismo oriundo de uma habilidade autodidata; a inquietude e a curiosidade que the remetiam à pesquisa permanente de materiais e processos; a disposição para executar trabalhos artesanais, mesmo que árduos; o preciosismo, na busca do perfeccionismo no acabamento dos trabalhos; registrem- 
se, ainda, as suas temáticas, geralmente humanistas e universais. Em termos formais, há a presença recorrente de elementos orgânicos, embora tenha ele declarado em aula, um dia, que era próprio das mulheres a abordagem de formas orgânicas.

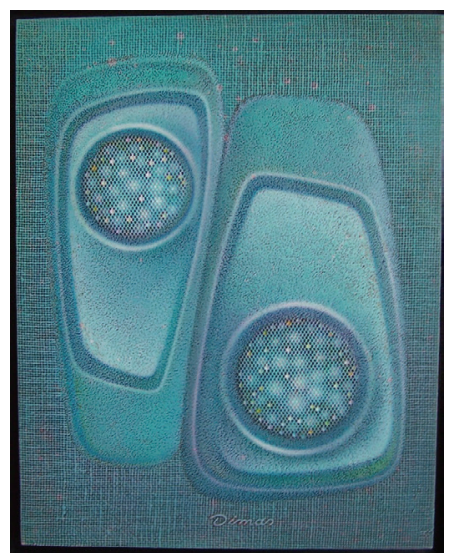

Figura 5 - Dimas Rosa. Sem título. 1978. Óleo sobre fibra de vidro. $38 x 46 \mathrm{~cm}$. Acervo Elisabeth Rosa.

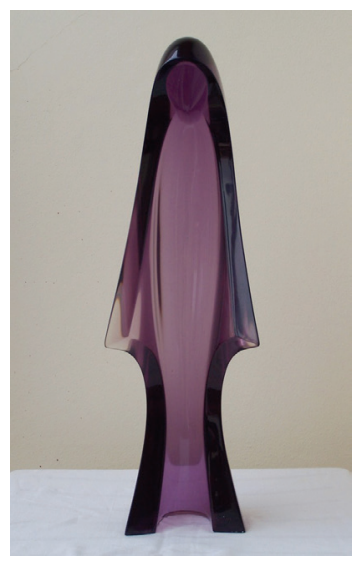

Figura 7 - Dimas Rosa. 1978. Madona. Acrílico. $60 \mathrm{~cm}$ de altura. Acervo Elisabeth Rosa.

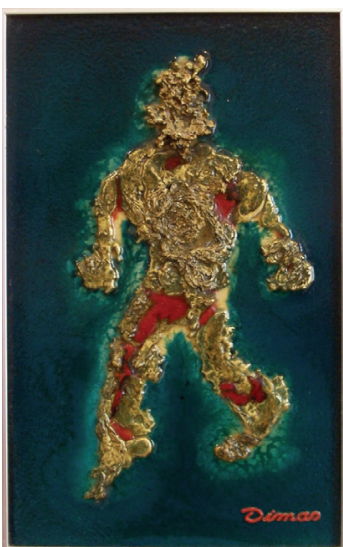

Figura 6 - Dimas Rosa. Sem título III. Sem data. Técnica mista. Acervo Elisabeth Rosa.

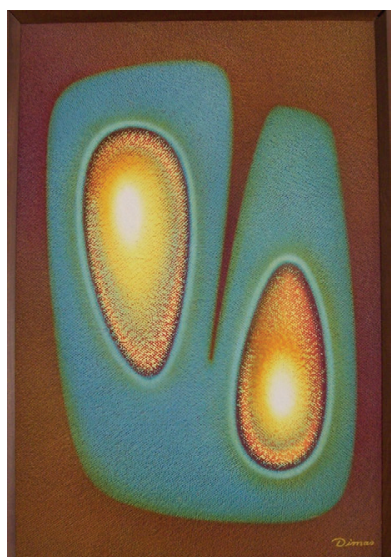

Figura 8 - Dimas Rosa. 1973. Forma III. Óleo sobre papeláo. $46,5 \times 68,5 \mathrm{~cm}$. Acervo Elisabeth Rosa. 
Dimas Rosa realizou diferentes exposições coletivas e individuais ao longo de sua carreira, sendo que as catalogadas totalizam trinta participaçóes. Uma das primeiras foi no 1o Salão de Artistas Plásticos de Florianópolis (1958), onde apresentou três retratos, um pintado a óleo e dois desenhos, ocasião na qual obteve "Menção Honrosa" (fig.10). Além desta, participou de outras mostras/exposiçóes coletivas em diferentes cidades de Santa Catarina; em Porto Alegre, na época em que fez seu curso de Graduação; em Curitiba; e no Rio de Janeiro. $\mathrm{Na}$ Assembléia Legislativa do Estado de Santa Catarina realizou duas exposiçóes individuais. Na primeira, em 1974, apresentou setenta e uma obras a partir de diferentes técnicas - escultura, cerâmica, pintura, serigrafias e desenhos, mostrando sua versatilidade; na segunda, três anos mais tarde, contou somente com esculturas.

Participou de comissóes organizadoras de dois eventos em várias edições: o Salão Estadual Universitário de Artes Plásticas, promovido pela UFSC, sendo que no primeiro deles participou também da Comissão Julgadora; e da Nacional Médica de Artes Plásticas, integrando o Júri de Seleção e Premiação, na sua primeira edição. Dimas foi membro de nove comissôes julgadoras de exposiçóes entre 1974 e 1983.

Em síntese, as principais mostras das quais Dimas Rosa participou foram:

1950: Exposição no Museu Centenário de Blumenau, Blumenau. 1958: 1o Salâo de Artistas Plásticos de Florianópolis, Florianópolis. 1970 a 1973: Exposiçóes Anuais do Instituto de Artes da UFRGS, Porto Alegre. 1974: V Coletiva de Artes Plásticas Barriga-Verde, Blumenau; Individual de Artes Plásticas, Assembléia Legislativa de Santa Catarina, Florianópolis. 1975: Abertura Artes Plásticas 75, Florianópolis; I Coletiva de Artistas Plásticos Brusquenses, Brusque; ARS-ARTIS - Coletiva de Artistas Plásticos Catarinenses, Florianópolis. 1976: 250 Anos de Cultura, Florianópolis; VI Coletiva de Artes Plásticas Barriga-Verde, Blumenau. 1977: Individual de Escultura, Assembléia Legislativa de Santa Catarina, Florianópolis; Coletiva de Artistas Catarinenses, inaugural da Galeria Victor Meirelles, Florianópolis; Panorama da Arte Catarinense, Balneário Camboriú; Miniquadros de Artistas Florianopolitanos, Florianópolis; 340 Salão Paranaense, Curitiba. 1978: Coletiva de Artistas Florianopolitanos, comemorativa do 140 aniversário de fundação 
da Universidade da FURB, Blumenau; Exposição do Centenário de Urussanga, Urussanga; 252 Anos de Cultura, Florianópolis; Coletiva de Artistas Florianopolitanos, Laguna; Artistas de Santa Catarina, Galeria Funarte Rodrigo M. F. de Andrade, Rio de Janeiro; Arte Barriga-Verde, Salão de Exposiçóes do BADEP, Curitiba; Nove do Grupo de Artistas Plásticos de Florianópolis - Vinte Anos Depois, Florianópolis; Três Escultores da Pesada, Joinville; Exposição de Miniquadros, Cerâmica e Reproduções Francesas, Florianópolis. 1979: Cinco Artistas Professores, Florianópolis; Exposição Pan’Arte, Balneário Camboriú. 1980: Nove do Grupo de Artistas Plásticos de Florianópolis, MASC, Florianópolis.

Para Dimas, a atividade artística era uma compulsão necessária para a vida, desde os primórdios e nas mais variadas culturas. A obra em sua essência está ligada às experiências do artista e é ele quem nos diz:

Acredito que uma obra de arte (qualquer uma realmente qualificada como tal), em última análise nada mais é que a coisificação de alguma significativa experiência de vida (significativa em relação ao aprimoramento do homem precisamente no que ele tem de mais humano: os seus sentimentos, as suas emoçôes, enfim, o seu espírito). E se diante de uma autêntica obra de arte, somos, cada um de nós, capazes ou não de captar-lhe o conteúdo, de sentir, de reviver a experiência de vida nela contida, trata-se aqui de uma questão de comunicação, de compatibilidade entre o emissor e o receptor; e o fato do espectador não ser sensível ao conteúdo da obra, não significa necessariamente que este não esteja lá. Concluo, portanto, que a qualidade primordial da arte é a originalidade; originalidade no sentido de estar vinculada às origens, de fluir das próprias raízes culturais, da própria vivência do artista (apud ARAÚJO, 1979, p. 247, grifo da autora).

Nesta citação, percebe-se claramente o pensamento de época, que passou a chamar-se modernista. Tal pensamento, que teve seus prenúncios no final do século XVIII, refletia o momento da sociedade, dela emanando uma força contra todo tipo de opressão e tradição, onde a Revolução Industrial teve seu lugar como estimulante do pensamento inovador e onde a invenção da fotografia dispensou as linguagens visuais da tarefa histórica de mimetizar a realidade, 
eternizar os feitos políticos, engrandecendo-os, e os soberanos e suas famílias, embelezando-os. Libertas desses grilhôes, as artes visuais puderam expressar o que ainda não existia, permitindo que os artistas se dedicassem às experimentaçóes. As novas ideias estavam no ar e à imaginação era facultada a inovação, o exercício de esgarçar os elementos constitutivos da visualidade, em proposiçóes até então desconhecidas. No Brasil, o movimento modernista tem sua certidão de nascimento situada na Semana de Arte Moderna de 1922 e, em Santa Catarina, os ventos modernistas chegam apenas na segunda metade dos anos 40, por meio do Grupo Sul, do qual Dimas Rosa fez parte.

\section{Dimas Rosa na visão da crítica}

Z mbora Dimas tenha declarado, em depoimento a Adalice Araújo (1979, p. 253), que suas obras "não despertavam qualquer interesse do público e da quase sempre omissa (para não dizer inexistente) crítica local", e por este motivo mesmo, parece relevante ouvir o que disse a crítica a respeito do trabalho de Dimas.

Isto porque a crítica de arte é sempre uma fonte profícua para conhecermos a visão de época, tanto sobre determinado artista, como sobre a concepção mesma de arte, pois nos seus julgamentos percebese claramente os paradigmas adotados. É evidente, estamos falando de críticos contemporâneos ao artista. Sobre Dimas Rosa encontramos críticas de Carlos Antonio Mancuso, Carlos Humberto Corrêa, Valmy Bittencourt, Adalice Araújo e Osmar Pisani. Assim como outros dados fundamentais para a escrita deste ensaio, os textos da crítica estão preservados nos arquivos que Dimas, pessoalmente, organizou.

Carlos Mancuso, crítico gaúcho, em texto datado de 1974, "Dimas é uma caso raro em nosso meio. Nele temos o exemplo vivo de um artista que se recusa a marginalizar-se". Ora, aí se observa concepção de arte do próprio crítico, uma vez que considera a fuga à marginalidade como um valor.

Segue, na sua crítica a Dimas, Carlos Mancuso:

Para Dimas a vida conta em seus mínimos detalhes. É um apaixonado por tudo o que existe. Seu trabalho traduz um refinamento técnico e um carinho todo especial pela forma elaborada. Sua formação humanística se reflete claramente 
na maneira disciplinada com que desenvolve seu trabalho, impondo seu modo e sua técnica. Sua arte é uma decorrência de sua vida e de sua visão de mundo.

O crítico faz uma alusão ao detalhismo de Dimas, ao refinamento formal e ao primor técnico, o que pode ser traduzido por um rigor praticamente científico, herança dos conhecimentos e dos anos de prática como professor de geometria. Entretanto, a técnica, que parece sempre destituída de qualquer "traço afetivo", no trabalho de Dimas não se configurava assim, o que pode ser observado em alusões à paixão pelas coisas da vida, ao carinho pela forma e à sua formação humanística, citados por Mancuso. Mas outro aspecto relevante da obra de Dimas é ressaltado por Mancuso, qual seja, a originalidade:

Não se perdeu, como outros, na busca da novidade pela novidade. Não há outro caminho para o artista senão buscar a originalidade de sua própria cultura, de sua própria experiência vital. Homens de valor como ele devem ser prestigiados e encorajados no seu trabalho criador, pois precisamos urgentemente duma nova ordem de valores visuais. Enquanto nadarmos na corrente interminável de elementos formais tomados de empréstimo, dificilmente teremos êxito na tarefa de dar forma a nossa própria cultura.

Observamos a carência de uma "nova ordem de valores visuais" no campo da arte e originalidade de Dimas como uma possibilidade, rompendo com os valores vigentes, tidos como importados, estranhos à nossa cultura. Outro aspecto a observar é o fato de o crítico conclamar seus leitores a estimular "homens de valor" como Dimas, o que de fato deve ter lhe faltado, uma vez que seus esforços eram dedicados mais ao ensino do que à produção artística propriamente dita, embora haja uma imensa área de intersecção entre ensino e arte.

A questão relacionada ao primor técnico, que só é possível ao artista que tem o espírito de pesquisador, foi também destacada em outra página da crítica, desta feita, de autoria de Carlos Humberto Corrêa, em 1975:

Conhecedor profundo dos materiais que usa e, principalmente 
da técnica de transformá-los em objetos com os quais transmite ideias e expressa sentimentos, ele chega aos limites de parecer confundir o trabalho árduo, penoso e intermitente de artesão com a rapidez fluídica e fria da forma industrial.

Eis aí assinalado outro traço muito presente na obra de Dimas: as técnicas adotadas eram, em sua maioria, resultado de intenso trabalho braçal e ele, como artista e também com seus alunos, muitas vezes construía ou montava moldes, ferramentas, equipamentos e até mesmo, uma fundição, como fez na UDESC. Entretanto, a rudeza do processo não se fazia presente no acabamento preciso e impecável. O equilíbrio dessa pretensa dicotomia não foi a única apontada por Carlos Humberto, que encontrou, no trabalho de Dimas, outras conciliaçóes aparentemente inconciliáveis:

Objetivamente, em sua produção parece chocar-se a teoria com a prática, o civilizado com o primitivo, o abstrato com o literário, a forma com a ideia, enfim, os dois sexos em seus conteúdos, amalgamando-se perfeitamente em açóes e atos que transmitem ao espectador a beleza da forma viva enquanto ser e, ao mesmo tempo, a dor passada pela transformação do material dos objetos enquanto mudança. Partindo basicamente do figurativo, Dimas Rosa transforma a aparência externa das coisas e das ideias para mostrá-las numa abstração lírica.

A noção do trabalho artístico de Dimas Rosa como amálgama de substâncias diversificadas foi evidenciada em outro texto crítico, este de autoria de Valmy Bittencourt, em 1977, bem como o domínio da técnica, especialmente naquela necessária para moldar a fibra de vidro:

Máquinas. Velocidade. Poluição. Poluição global. Salário. Consumo. Contas. Vida. E neste cadinho infernal fazer arte é ser um acrobata do espírito. E mais, ser um artista honesto, autêntico e original é algo extraordinário. Isto é o que eu penso de Dimas. Para mim o seu forte é a escultura. O primeiro impacto é o material que realiza a sua arte [...] fibra de vidro. Hoje ele é dono deste material. Aliás, já lhe disse que poucos em nosso país dominam tão bem esta técnica. O tema central das esculturas é o ser humano. Seus mistérios. Suas faces. A magia das máscaras. Tema primitivo tratado como material novo, e com o toque de um grande escultor. 
Embora os diversos críticos estejam de acordo em relação a determinados aspectos da obra de Dimas Rosa, cada um deles acaba ressaltando alguma coisa específica. São dados visuais que estão presentes nos seus trabalhos e podem ser aferidos ao se observar hoje em dia, como no caso do volume que ele consegue conferir aos trabalhos bidimensionais. É o que consta de sua crítica de 1978:

Relevo, textura e cor definem os trabalhos de Dimas Rosa, quase todos abstratos. No entanto, por ser essencialmente um escultor, alguns de seus trabalhos trazem a marca do volume e do espaço. Trata-se de um artista que vem pesquisando e aplicando há muito tempo em Santa Catarina, novos materiais em escultura: poliéster, epóxi e fibra de vidro

Data também de 1978 o texto de Edson Machado, que igualmente ressalta os novos materiais, tão caros ao modernismo, nos seguintes termos:

representada por Dimas Rosa, a figura do homem revela o automatismo através das enormes máscaras angulosas de expressóes contidas, reflexos do homem moderno, de consumo, de padronização. Sua escultura transmite o primitivismo do ser num contexto civilizado, usando a matéria prima extremamente industrial e moderna - resina de poliéster e fibra de vidro - de forma artesanal, resultando um refinamento técnico e elaborado.

No livro "Mito e Magia na Arte Catarinense", a professora e crítica de arte paranaense Adalice Maria de Araújo dedica espaço a Dimas Rosa, no texto "Dimas Rosa: Máscaras/Técnica e Magia", onde explora diversos aspectos relacionados ao artista, inserindo trechos de um depoimento a ela concedido, além do que tece seus próprios comentários acerca da obra do artista, destacando a fase das máscaras:

O máximo interesse em sua obra reside nos trabalhos tridimensionais: "Série de Máscaras" que vem executando a partir de 74 , na qual ocorre a uniáo entre a pesquisa de material, da mais absoluta contemporaneidade, a um sentido mágico, primitivo. Póe a descoberto o sentido cosmogônico que a máscara encerra, como crisálida de que o homem se vem servindo, através dos tempos, para manifestar as suas subjetividades. 
O trecho acima faz parte do acervo do artista, cujo acesso nos foi dado pela família. Entretanto, no mesmo excerto de Adalice Araújo, publicado no seu livro "Mito e Magia na Arte Catarinense" (1979, p. 245, grifo da autora), o parágrafo não se encerra na palavra "subjetividades"; a frase é acrescida do seguinte: “...mais profundas, que lhe vem marcando o id e o ego".

Ora, se na transcrição do texto, datilografada pelo próprio Dimas, o último trecho foi suprimido, não é necessário ser um semioticista para deduzir que ele não concordava com os últimos termos, fundamentados na psicanálise.

Adiante, seguem-se outras observações de Adalice Araújo, as quais são exatamente coincidentes, tanto no livro quanto na transcrição datilografada por Dimas:

Para Dimas Rosa, o suporte deve se ajustar à forma, tipo e gênero da obra: concluindo-se que seu conteúdo não pode ser dissociado. A preocupação que tem pelo perfeccionismo técnico provém da certeza que quanto mais o artista conhece os materiais e os domina na sua manipulação, mais liberdade expressiva terá. Daí a acreditar que durante a execução do trabalho ocorre um mudo processo dialético entre o artista e o material, o qual muitas vezes reage e provoca modificaçóes nas soluçôes formais propostas, sugerindo outros caminhos. Está aí, implícita, uma relação simbólica entre o macro e microcosmo. Este princípio mito-técnico, associa-se a um resíduo arcaico [...].

Nestas consideraçóes, Adalice Araújo reitera uma das principais características da obra de Dimas Rosa, a qual não passou despercebida pala crítica, no seu conjunto: o rigor da técnica, que o levou ao domínio dos materiais, o qual, por sua vez, possibilitava o perfeccionismo formal, (no sentido Greco-romano da expressão) que era inerente à sua criação. Esta característica - ou este conjunto de características, porque nem todo rigor leva ao perfeccionismo, no sentido Greco-romano - foi marcante e é ela que permite considerar Dimas Rosa como um modernista, um contemporâneo do seu tempo. 


\section{Dimas Rosa: o ser humano}

imas Rosa nasceu em Itajaí, Santa Catarina, em 10 de março de 1931. Era filho de Campello Rosa e Vergínia Grotti Rosa, tecelóes. Viveu em Brusque e depois, em Florianópolis, no mesmo Estado.

Nos primeiros anos escolares, Dimas passava a maior parte do tempo desenhando, segundo ele mesmo, "com o incentivo de alguns professores e a tolerância de outros” (ARAÚJO, 1979, p. 249). Depois, passou a pintar, usando tinta óleo para pintura de casas e, como suporte a madeira, porque não sabia da existência de tinta para pintura nem de telas. Foi só com 15 anos que soube, pelo amigo Eusébio Maestri, da existência das bisnagas e telas.

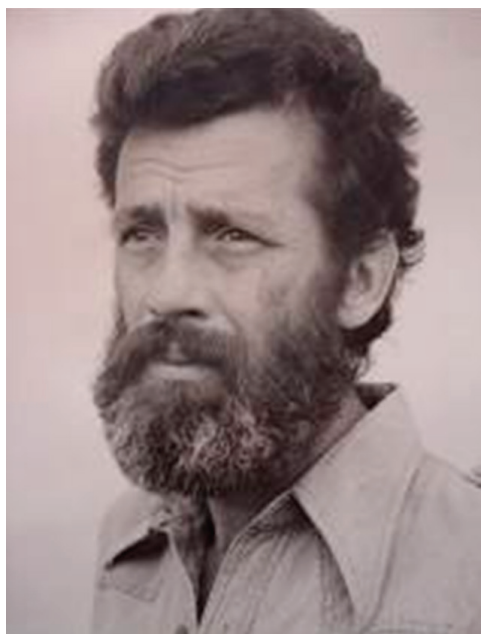

Figura 9 - Fotografia de Dimas Rosa na maturidade. Sem data. Acervo da Fundação Catarinense de Cultura/FCC.

No início da sua vida profissional, em Brusque, precisou deixar o desenho e a pintura de lado. Dada a sua inquietude, foi marceneiro, trabalhou em latoaria e fundição, em fiação e estamparia de tecidos, com adornos de cerâmica e estofamento de móveis, além de ter sido lenhador, jardineiro, garçom, locutor de rádio, músico de orquestra de danças e, 
por último vendedor. Como se pode observar, mesmo tendo deixado a produção artística de lado, experimentava, na atividade de produção utilitária, materiais e formas que viriam a ser traduzidos para linguagem artística, posteriormente. Excetuando umas poucas, a maioria das ocupaçóes era voltada para produtos estéticos, ainda que utilitários, como a jardinagem, a estamparia, a cerâmica e mesmo a marcenaria.

Vindo morar em Florianópolis, tornou-se funcionário público do antigo IAPC (Instituto de Aposentadoria e Pensóes dos Comerciários), período que ele considerou "certamente o pior, o mais maçante trabalho que já experimentei” (ARAÚJO, 1979, p. 250). Em seguida, 1954, graças a sua habilidade no desenho, de acordo com o próprio Dimas, ingressou no magistério, atuando até a aposentadoria. Paralelamente, por diletantismo, segundo ele, percorria oficinas, onde trabalhou para aprender, como voluntário ou estagiário: solda de metais, chapeação, eletricidade, mecânica de automóveis.

No estaleiro do $5^{\circ}$. Distrito Naval aprendeu carpintaria e desenhou embarcaçóes, chegando a projetar e construir um veleiro de oceano que venceu a primeira regata que disputou. Paralelamente, ainda foi desenhista de projetos, produziu material didático e técnico em recursos audiovisuais, além de cultivar plantas ornamentais, tendo chegado a ser um dos principais orquidófilos de Florianópolis.

Ainda no seu depoimento a Adalice Araújo, vale a pena preservar as próprias palavras de Dimas sobre sua decisão de ingressar no Instituto de Artes da UFRGS, para cursar Artes Plásticas:

Em 1969, deu-me um estalo e parei para pensar. Acho que pela primeira vez me sentia realmente cansado. Deixara de vibrar com as coisas que fazia, e não me agradavam as perspectivas do futuro. Começava a compreender o erro da dispersão que consumia os meus esforços, a pressentir que ocupaçóes diversificadas não me levariam a nada. Percebi, enfim, que me distanciava cada vez mais da minha vocação mais acentuada e, consequentemente, de mim mesmo. Decidi então, já beirando os quarenta anos, mudar de vida, concentrá-la na arte. [...] vendi ou larguei quase tudo que tinha (inclusive a casa que com tanta luta acabara de construir) e, juntamente com minha mulher e os três filhos, mudei-me para Porto Alegre [...] (ARAÚJO, 1979, p. 251). 
Ao terminar o curso superior, durante o qual foi estagiário em uma das disciplinas, foi agraciado com uma bolsa por ter obtido o primeiro lugar no curso de Artes Plásticas e também o primeiro entre todos os concluintes dos cursos nas três áreas artísticas (Música, Teatro e Artes Plásticas), no Instituto de Artes da UFRGS. Ao retornar a Florianópolis, inicia-se um longo e mais focado período da sua vida: dedica-se ao Magistério Superior, no então recém-criado Curso de Educação Artística da UDESC, por força de Lei Federal 5.692/71, que gerava uma demanda de professores para a nova disciplina criada na Educação Básica. Paralelamente, ocupa-se apenas, se é que pode assim dizer, da produção artística, sentindo-se então mais à vontade como artista, após a titulação acadêmica e o convívio com o ambiente cultural de Porto Alegre.

Isto porque, embora a obstinação pela criação de formas, com os mais diversificados materiais, venha desde os bancos escolares, para Dimas, durante um longo período, seu ideal plástico

se resumia então na capacidade de representar os objetos com fidelidade fotográfica. E creio que algumas vezes estive perto disso, sobretudo num autorretrato (o único que fiz) a bico de pena $[. .$.$] que realmente pode ser confundido com uma foto$ (ARAÚJO, 1979, p. 252).

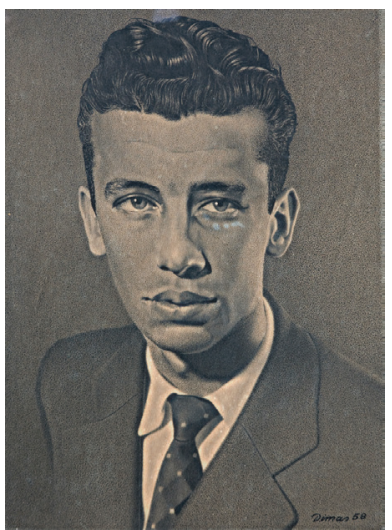

Figura 10 - Dimas Rosa. Autorretrato. 1958. Bico de pena sobre papel canson. 24x32cm. Acervo Dimas Rosa. 
Tal concepção de arte levou-o a ter certo distanciamento dos ideais do Grupo Sul, uma vez que seu autodidatismo mostravalhe apenas um caminho, o figurativo acadêmico, já que aqui, em Santa Catarina, os "acontecimentos do porte da semana de 22 eram simplesmente ignorados” (ARAÚJO, 1979, p. 252), embora já estivéssemos na década de cinquenta.

A respeito de suas relaçóes com o Grupo Sul, Dimas Rosa diz ter sofrido um grande impacto, já que o Grupo combatia o academicismo que ele praticava. Disse ele:

comecei a perceber a pobreza e o anacronismo de minhas ideias sobre arte. Sempre me adaptara com facilidade às situaçôes novas, desta vez, porém, sentia-me perturbado, confuso. Não conseguia vibrar com a maior parte dos trabalhos que os membros do Grupo faziam ou admiravam, mas por outro lado, precisava admitir que aquilo que eu próprio vinha fazendo já não tinha qualquer sentido [...] (ARAÚJO, 1979, p. 252).

A aceitação de Dimas no Grupo só foi possível porque a principal regra do Grupo Sul era não ter regras. E também, Dimas Rosa omitiu em seu depoimento, porque o ser humano que nele habitava jamais seria objeto de qualquer censura, não obstante produzir trabalhos com uma linguagem distinta daquela pregada pelo Grupo. Dimas avaliou, mais tarde, que sua participação no Grupo foi mais intelectual do que artística propriamente, pois durante o período de existência do Grupo Sul ele pouco produziu (ARAÚJO, 1979, p. 252):

frequentemente nos reuníamos na Livraria Anita Garibaldi (para nós, a livraria do Salim), e ali, além da oportunidade de conversar e selecionar bons livros sobre arte, mostrávamos os trabalhos que íamos fazendo, discutíamos suas qualidades, aconselhávamos e éramos aconselhados por eles. [...] apesar da maioria não gostar do meu trabalho, nem eu do deles, em pouco tempo todos me aceitaram como um deles.

O fato é que Dimas Rosa, produzindo pouco no período, pelos motivos já expostos, fazia parte do Grupo Sul, mas de um modo até certo ponto, acessório. Participava das discussóes teóricas, mas não se encorajava a produzir e colocar em debate sua própria produção, cuja 
repercussão já antevia.

O conceito acerca de alguém ou de algo é, até certo ponto, um tanto subjetivo. Mas nem por isso pouco importante: é o caso das marcas dos produtos, no mercado contemporâneo. No caso dos artistas visuais, até hoje, sua própria imagem e até sua vida privada constituem-se em atributos que lhe atribuem valor. A excentricidade de um artista, por exemplo, ainda hoje é fator de agregação de valor, seja ele um músico, um ator ou um artista visual. E isto não é de hoje. E escândalos vêm sendo fabricados para produzir notoriedade no mundo da produção cultural.

Dimas Rosa, participante do Grupo Sul, era um artista bem comportado, convencional, objetivo, amante da representação do natural: um acadêmico na modernidade. Mais tarde, quase vinte anos depois, devidamente ungido com um título acadêmico de artista, retoma sua produção, prenhe das inovaçóes trazidas de um curso de renome, tendo vivenciado a arte em um ambiente cultural muito mais arejado do que a provinciana, ainda, Florianópolis. Mas aqui, o conceito já estava formado em torno do seu nome; e por mais inovadoras que fossem suas técnicas, abordagens e temáticas, Dimas era tido como um acadêmico, um artista formal, e sua obra, como institucionalizada. E assim, não recebeu a consideração devida. Esta obra ainda está aberta a estudos e novas leituras, pois seu valor ainda não foi devidamente reconhecido.

Dimas certamente não se frustrou, pois, paralelamente, se entregava, nas suas palavras, "com entusiasmo", ao Magistério [...], "sempre com renovado interesse, sem nunca me entregar à rotina" (ARAÚJO, 1979, p. 250). Embora preferisse inverter a situação, que seria "trabalhar a maior parte do tempo no ateliê e dar aulas nas horas de folga" (ARAÚJO, 1979, p. 256). Observe-se que para ele, dar aulas poderia ser considerado ocupação para horas de folga. Daí, muitos jovens artistas se formaram, outros tantos professores de arte, hoje ainda atuando, inclusive, muitos constituindo a pujança da área de Artes Plásticas na UDESC, na graduação e na pósgraduação, atualmente uma referência nacional. Porém, nós todos é que deveríamos nos sentir frustrados, por não ter entendido a força e o vigor de uma arte que mesclava o árduo trabalho artesanal com seu respectivo conceito, dentro de uma lógica formal, coerente com sua contemporaneidade modernista. 
E Dimas estava lá, com seu terno bem delineado, à moda da época, no vernissage que desvendava ao público seu rigor e sua técnica aprimorados, constantes nos seus trabalhos. No mesmo vernissage, nenhum fato estranho, nenhuma quebra de paradigmas, nem na obra, nem na vida de um ser, sobretudo, humano.

Fazendo-se uma leitura atenta dos depoimentos que Dimas Rosa deixou, pode-se perceber que ele chegou a antever o fim do modernismo, o fim da estética tinha como referência, instaurando outros modos de ser da arte. E vislumbrou alternativas, embora, é claro, sustentadas pelo pensamento da sua época, pois apesar de pregar que a arte deveria refletir a própria vida, a ênfase estava, novamente, no material. Em certo momento, declarou:

[...] estou convencido que a arte [...] deve, tanto quanto possível, refletir nossa própria vida. Ora, inegavelmente, a cada dia presenciamos nos nossos objetos de uso pessoal, na nossa casa, nos nossos instrumentos e locais de trabalho, na nossa cidade, enfim, em quase tudo a nossa volta, a progressiva substituição dos materiais naturais pelos plásticos. Por que então não aplicá-los, como veículo de expressão de nossas manifestaçôes artísticas? (ARAÚJO, 1979, p. 254).

Em outro momento, atribuindo a falta de interesse pela arte à necessidade da luta pela sobrevivência, Dimas fala mesmo em morte da arte, ressaltando que se tratava da morte de uma arte conforme entendida naquele tempo, ou seja, a arte modernista; mas não lamentava; ao contrário, considerou-a "a melhor forma de morte", pois, na sua perspectiva, a morte seria a transformação, mais precisamente, a transformação da arte em novas formas de vida para a humanidade:

Penso que quando a humanidade superar a luta pela subsistência, o seu interesse se voltará para as necessidades do espírito; então se reconhecerá toda a grandeza da arte e todos chegarão a fazê-la e fruí-la. Viver-se-á com arte. [...] Como se vê, minha imagem prospectiva não é afinal assim tão fantasiosa. É verdade que, por um lado, ela significa a morte da arte, tal como a entendemos hoje: mas haveria melhor forma de morte, que a de ser transformada em forma de vida de toda a humanidade? (ARAÚJO, 1979, p. 256). 
Dimas Rosa foi casado com Elisabeth Rosa, a Betinha, como a chamava, sua única esposa, desde 17 de outubro de 1953, ficando casados, portanto, 42 anos, até que a morte os separou.

Com Dona Betinha, Dimas Rosa teve três filhos, Dimas Ricardo, Roberto e Rosângela, os quais lhes deram cinco netos: Lucas Bernardes Rosa e Bruno Bernardes Rosa, filhos de Dimas Ricardo; Monique Rosa e Karine Iris Rosa, filhas de Roberto; e Tatiana Rosa Cirio, filha de Rosângela.

Dimas Ricardo Rosa, além de nos fazer lembrar seu pai por diversos aspectos de seu modo de ser, seguiu-o sendo professor do Centro de Artes da UDESC, herdando suas disciplinas voltadas à escultura, ainda que lhes imprimindo a atualizaçáo que o tempo exige. Também como Dimas Rosa, Dimas Ricardo Rosa foi Chefe do Departamento de Artes Plásticas do Centro de Artes da UDESC.

Segundo depoimento de Dimas Ricardo,

o pai era um homem querido pelas pessoas porque sabia ouvilas; contudo, o que mais as pessoas admiravam nele, era o carinho e o capricho com que ele fazia as coisas; ele era muito organizado e a ordem com que tratava todas as coisas de sua vida,era bonito de ver (informação verbal)

Lucas Bernardes Rosa, filho de Dimas Ricardo e neto de Dimas Rosa, hoje, em 2010, é aluno do Curso de Design do Centro de Artes da UDESC e, segundo depoimentos de seus professores, passa as aulas desenhando, como fazia seu avô, quando aluno.

Dimas Rosa morreu em Florianópolis, em 26 de janeiro de 1995, aos 63 anos de idade; talvez "a melhor forma de morte", pois segundo ele afirmou, em relação à arte, a melhor morte seria a transformação em novas vidas. Foi o que Dimas conseguiu, por sua descendência, pelo exemplo e ensinamentos aos seus alunos e pelos trabalhos artísticos que deixou: sim, transformação, ou seja, mutaçóes das formas, físicas, éticas e estéticas. Sua obra artística ainda está por ser devidamente explorada e melhor compreendida. Mas a potência do seu ser reverbera entre aqueles que tiveram o privilégio de com ele conviver - e aprender. ${ }^{9}$ Depoimento fornecido por Dimas Ricardo Rosa, filho de Dimas Rosa, por correio eletrônico em 13 de
janeiro de 2010 . 


\section{Referências}

ARAÚjO, Adalice Maria de. Mito e Magia na Arte Catarinense. Florianópolis, Governo do Estado de Santa Catarina/IOESC, 1979. CORRÊA, Hassis (coord.). Catálogo da exposição "Nove do Grupo de Artistas Plásticos de Florianópolis 1958-1978: 20 anos depois." Florianópolis: IOESC, 1978. Não paginado.

CORRÊA, Carlos Humberto. Catálogo da exposição "1958/78- Grupo de Artistas Plásticos de Florianópolis, em homenagem aos 20 anos do grupo, realizada no período de 21 a 30 de setembro de 1978, na Assembléia Legislativa do Estado de Santa Catarina.

MAKOWIECKY, Sandra. Aldo Beck: a narrativa visual de uma cidade e sensibilidade moderna. DAPesquisa, v. 3, n. 2. p. 1-9, Ago/2008 a jul/2009. Disponível em: <http://www.ceart.udesc.br/ revista_dapesquisa/volume4/numero1/ plasticas/aldobeck.pdf >. Acesso em: 13 jan. 2010.

; CHEREM, R. M.. Academismo e Modernismo em Santa Catarina. 1. ed. Florianópolis: Editora da UDESC, 2010. v. 1. 705p. CD-ROM.

MUSEU DE ARTE DE SANTA CATARINA. Florianópolis: Fundação Catarinense de Cultura. Apresenta informaçóes virtuais, textos e obras de artistas catarinenses; do Grupo Sul; modernismo catarinense, dentre outros. Disponível em: <http://www.alquimidia. org/masc >. Acesso em 15 de jan. 2010.

ROSA, Dimas R. Depoimento sobre Dimas Rosa [mensagem pessoal]. Mensagem recebida por<ramalho@floripa.com.br> em 13 de jan. 2010 . 